\title{
Eye Strain from Convergence Insufficiency
}

\author{
R. S. MAHTO
}

\section{Summary}

Eye strain and headache are common ocular symptoms, and the main cause in persons aged 15 to 40 is convergence insufficiency. It is more common in females than in males. Many patients are supplied with glasses for eye strain without the causative convergence insufficiency being treated. The treatment in most cases is orthoptic exercises.

\section{Introduction}

The eyes converge when looking at an object nearer than 6 metres, and the nearest point to which they can converge is about $10 \mathrm{~cm}$ in front of the baseline drawn from the apex of both corneas. Failure to achieve and maintain this degree of convergence without undue effort is known as convergence insufficiency. The aetiology of the condition is ill understood, but it is usually idiopathic. Some cases are associated with latent divergent strabismus and in others general disease or debility may be the cause.

Convergence insufficiency may be symptomless, but sufferers from it who do close work usually complain of "eye strain"-blurring of print when reading, running of words into each other, eye ache, headache, and diplopia.

Convergence is easily measured objectively by asking the patient to keep looking at the examiner's finger-tip as it is slowly moved towards the patient's nose from a distance of $30 \mathrm{~cm}$ in front. Normally the eyes converge without hesitation or discomfort. In cases of convergence insufficiency the patient may complain of discomfort and either one or other eye moves outward after first converging or the patient is unable to converge to $10 \mathrm{~cm}$. In extreme cases any attempt to measure convergence results in fainting and sickness.

According to Duke-Elder (1969) the clinical importance of convergence insufficiency has been recognized from the time of von Graefe, and more than a hundred years later it is sad to find patients unnecessarily wearing glasses while the underlying condition has never been treated.

The treatment for convergence insufficiency and latent strabismus is orthoptic exercises.

\section{Patients}

Out of 310 patients aged under $\mathbf{4 0}$ seen by me in a period of two years $34(11 \%)$ had varying degrees of convergence insufficiency, and 14 of them had previously had their eyes tested elsewhere and were wearing glasses for eye strain (see Table). They were aged 15 to 28 when their symptoms of eye strain developed.

Twenty-four $(70.5 \%)$ of the 34 patients were women and 10 $(29.4 \%)$ were men. The glasses they were wearing were all within +0.7 or -0.5 dioptre sphere with or without a cylinder of under \pm 0.5 dioptre. Stronger glasses would not have been tolerated. One patient had worn her glasses for 15 years with no difference to her ocular symptoms because she thought that

Bath Eye Infirmary, Bath

R. S. MAHTO, F.R.C.s., D.o., Assistant Ophthalmologist otherwise she would harm her eyes. This seems to be a popular misconception. After a course of orthoptic exercises she was symptom-free and did without glasses.

Clinical Details of 14 Patients Supplied with Glasses for Eye Strain Due to Convergence Insufficiency

\begin{tabular}{|c|c|c|c|c|c|c|}
\hline \multirow{2}{*}{\multicolumn{2}{|c|}{$\begin{array}{l}\text { Case } \\
\text { No. }\end{array}$}} & \multirow{2}{*}{ Sex } & \multirow{2}{*}{$\begin{array}{c}\text { Age at } \\
\text { First Test }\end{array}$} & \multirow{2}{*}{$\begin{array}{l}\text { Years } \\
\text { Glasses } \\
\text { Worn }\end{array}$} & \multicolumn{2}{|c|}{ Glasses Worn } \\
\hline & & & & & Right & Left \\
\hline 1 & .. & F. & 18 & 15 & $\frac{-0.25}{+0.50} 90^{\circ}$ & $\frac{-0.25}{+0.75} 90^{\circ}$ \\
\hline 2 & . & F. & 18 & 6 & $\frac{-0.50}{+0.50}-130^{\circ}$ & $\frac{-0.50}{+0.50} 70^{\circ}$ \\
\hline 3 & . & M. & 21 & 2 & $\frac{0}{+0.25}-180^{\circ}$ & $\frac{0}{+0.25}-175^{\circ}$ \\
\hline 4 & . & F. & 26 & 7 & $\frac{0}{+0.25} 60^{\circ}$ & $\frac{+0.25}{+0.50} 40^{\circ}$ \\
\hline 5 & . & M. & 27 & 5 & $\frac{+0.50}{+0.50} 90^{\circ}$ & $\frac{+0.50}{+0.50} 90^{\circ}$ \\
\hline 6 & . & F. & 26 & 12 & $\frac{-0.25}{-0.25}-180^{\circ}$ & Plano \\
\hline 7 & .. & F. & 20 & 7 & +0.75 & +0.75 \\
\hline 8 & . & M. & 28 & 3 & +0.50 & +0.50 \\
\hline 9 & . & F. & 21 & 6 & $\frac{+0.25}{+0.25} 160^{\circ}$ & +0.50 \\
\hline 10 & $\cdots$ & F. & 15 & 8 & $\frac{+1.00}{-0.50} 160^{\circ}$ & $\frac{+0.50}{-0.25} 160^{\circ}$ \\
\hline 11 & .. & M. & 27 & 1 & $\frac{+0.75}{-0.50} 150^{\circ}$ & $\frac{+0.50}{-0.50}$ \\
\hline 12 & .. & F. & 20 & 5 & $\begin{array}{l}+0.75 \\
-0.50\end{array}$ & $\begin{array}{l}+0.75 \\
-0.50\end{array}$ \\
\hline 13 & . & M. & 27 & 7 & $\frac{-0.50}{+0.50} 90^{\circ}$ & $\frac{-0.50}{+0.50} 115^{\circ}$ \\
\hline 14 & . & F. & 20 & 6 & $\frac{+0.50}{+0.50}-180^{\circ}$ & $\frac{0}{+0.50} 175^{\circ}$ \\
\hline
\end{tabular}

\section{Discussion}

Small corrections such as these patients had make no difference to the vision and they do not cause discomfort.

In persons aged over $\mathbf{4 0}$ presbyopia is the major cause of eye strain, and glasses should be prescribed. It is rare for a refractive error not to be detected by the age of 15 because of the examinations under the school medical service. Therefore any patient aged 15 to 40 complaining of eye strain is most likely to have convergence insufficiency or latent strabismus. A simple diagnostic test is of help: when the vision is $6 / 6$ a refractive error is unlikely and the case is probably one of convergence insufficiency or latent strabismus.

Nature has made nothing perfect, and the eye is no exception. Hypermetropia of +0.50 dioptre is within normal physiological limits. Astigmatism of +0.50 in the vertical meridian and -0.50 in the horizontal meridian is quite common and within physiological limits. These minor degrees of refractive error never produce eye strain.

\section{Conclusion}

Patients aged under 40 should be advised to have their first eye test from an ophthalmologist. 
When symptoms persist after glasses have been prescribed the eye strain is probably due to convergence insufficiency and not to refractive error. It would help if all patients supplied with glasses under the general ophthalmic service of the National Health Service were given a form advising them to see their doctor again if their symptoms are not relieved. The cause of their condition would then be recognized and treatment arranged.

Duke-Elder, S. (1969). The Practice of Refraction, p. 157. London, Churchill.

\title{
Rapid Blood Ketone Body Estimation in the Diagnosis of Diabetic Ketoacidosis
}

\author{
K. G. M. M. ALBERTI, T. D. R. HOCKADAY
}

British Medical fournal, 1972, 2, 565-568

\section{Summary}

Different methods of assessing ketone body concentrations in blood and plasma of ketoacidotic patients have been compared. We confirmed that Ketostix reacts strongly with acetoacetate, giving a useful range of 0 to $10 \mathrm{mM}$ for plasma acetoacetate, that acetone reacts weakly, and that 3-hydroxybutyrate does not react at all. Plasma Ketostix readings correlated only moderately well with enzymatically determined whole-blood acetoacetate. All samples giving a +++ reaction contained more than $1.6 \mathrm{mM}$ acetoacetate while only 4 out of 21 samples showing 0 contained more than $0.4 \mathrm{mM}$. Comparison of Ketostix readings with total blood ketone body content showed poor correlation. One reason for this was the large variation in the ratio of 3-hydroxybutyrate to acetoacetate in ketoacidosis; another was that often Ketostix had been stored in such a way that they had become damp, which impairs their reliability. If the Ketostix reading and estimation of the blood $\mathrm{pH}$ show a discrepancy we suggest that an enzymatic assay should be used to determine the ketone bodies and lactate.

\section{Introduction}

The estimation of blood "ketone bodies" (acetoacetate, 3hydroxybutyrate) as well as of blood glucose is needed for the assessment of the severity of diabetic coma. This measurement is also essential for the early exclusion of hyperosmolar non-ketotic diabetic coma. The initial insulin requirements are often based on the extent of the existing hyperketonaemia (Duncan and Gill, 1953; Hockaday and Alberti, 1972).

The accurate enzymatic measurement of blood ketone bodies takes at least two hours, and a more rapid method is required. An indication is given by the arterial blood $\mathrm{pH}$, but this can be misleading if acidaemia is due to lactic acid, and the blood buffering capacities of individuals differs widely. Ketostix has been used as a more specific measure of ketoacidosis (Watkins and Fitzgerald, 1968). It is rapid, the range is of the right magnitude, and added sensitivity can be gained by prolonging the incubation to 30 seconds. However, Ketostix is based on a nitroprusside method measuring acetoacetate and to a lesser extent acetone, but not 3-hydroxybutyrate. Thus when the

Radclifie Infirmary, Oxford K. G. M. M. ALBERTI, D.PHIL., B.M., B.CH., Research Officer, Nuffield

T. D. R. HOCKADAY, D.PHIL., F.R.C.P., Consultant Physician 3-hydroxybutyrate to acetoacetate ratio is abnormally high Ketostix will give a false low estimate of total ketone bodies (Marliss et al., 1970; Alberti et al., 1971).

We have used Ketostix in both the diagnosis and the management of 50 cases of diabetic coma and precoma, and have simultaneously estimated acetoacetate and 3-hydroxybutyrate enzymatically in whole blood. The results shown below indicate that the accuracy of Ketostix in practice is not so great as has previously been suggested (Watkins and Fitzgerald, 1968). Possible reasons for this and means for improving the accuracy are discussed. In addition, we report the results of direct enzymatic measurements of ketone bodies in plasma without previous deproteinization; this allows a rapid assessment of the degree of hyperketonaemia. A similar method has been described for rat plasma (McGarry et al., 1970).

\section{Methods}

\section{KETOSTIX}

The Ketostix strips used were those available in the wards and emergency room of the Radcliffe Infirmary. It was felt that these should be used, rather than a special supply, so as to reflect the practice in most hospitals. Ketostix readings were generally made by one of us but also include readings by both house staff and members of the department of clinical biochemistry. Readings were taken at 15 seconds and expressed as negative, trace,,+++ , and +++ . In some cases plasmas giving +++ readings were diluted 1 in 2 with tap-water and a further Ketostix estimation was made.

\section{ENZYMATIC METHOD FOR KETONE BODY ESTIMATION}

(a) Whole blood.-Immediately after it was drawn $5 \mathrm{ml}$ of venous blood was added to $5 \mathrm{ml}$ of $10 \%(\mathrm{w} / \mathrm{v})$ perchloric acid $\left(\mathrm{HClO}_{4}\right)$ and the mixture instantly refrigerated. Removal of the denatured proteins by centrifugation and neutralization of the supernatant with $30 \% \mathrm{KOH}$ to $\mathrm{pH} 7$ were performed within 72 hours. Acetoacetate was estimated immediately after neutralization and 3-hydroxybutyrate later. Venous blood acetoacetate and 3-hydroxybutyrate were estimated by enzymatic methods (Williamson et al., 1962). For acetoacetate a known volume of the neutralized supernatant $(0.05$ to $1 \mathrm{ml}$, depending on the expected acetoacetate content) was pipetted into a spectrophotometric cuvette and made up to $1 \mathrm{ml}$ with water, if necessary. To this was added $1 \mathrm{ml}$ of "cocktail" containing $1.25 \mathrm{ml}$ of $0.5 \% \mathrm{NADH}$ (reduced nicotinamide adenine dinucleotide) to every $25 \mathrm{ml}$ of $0 \cdot 1 \mathrm{M}$ potassium phosphate buffer, $\mathrm{pH} 7$. Two baseline spectrophotometric readings were then made at $340 \mathrm{~m} \mu$. Next $0.01 \mathrm{ml}$ of 3-hydroxybutyrate dehydrogenase (2.5 $\mathrm{mg} / \mathrm{ml}$; Boehringer Mannheim $\mathrm{GmbH}$, Germany) was 